\title{
Properties of some thermally modified wood species
}

\begin{abstract}
The objective of the study was to investigate the influence of heat treatment and exposure time on surface roughness, wettability, shear strength and hardness of rubberwood, Eastern redcedar and red oak samples. The anatomical structure of each species was also observed using scanning electron microscope (SEM). All specimens were exposed to two different temperature levels, namely $120^{\circ} \mathrm{C}$ and $190^{\circ} \mathrm{C}$ for 2 and $8 \mathrm{~h}$. Red oak samples had the most enhanced surface quality along with less wettability characteristics followed by rubberwood and Eastern redcedar specimens as function of increased heat exposure. On the other hand, it appears that heat exposure adversely affected shear strength and hardness properties of all three types of samples. These two properties of heat treated samples had reduction values ranging from $52.7 \%$ to $69.4 \%$ and $10.8 \%$ to $33.3 \%$, respectively as compared to those of control samples.
\end{abstract}

Keyword: Heat treatment; Thermally modified wood 